\title{
Approaches for enhancing information sharing between government and communities in Western Cape
}

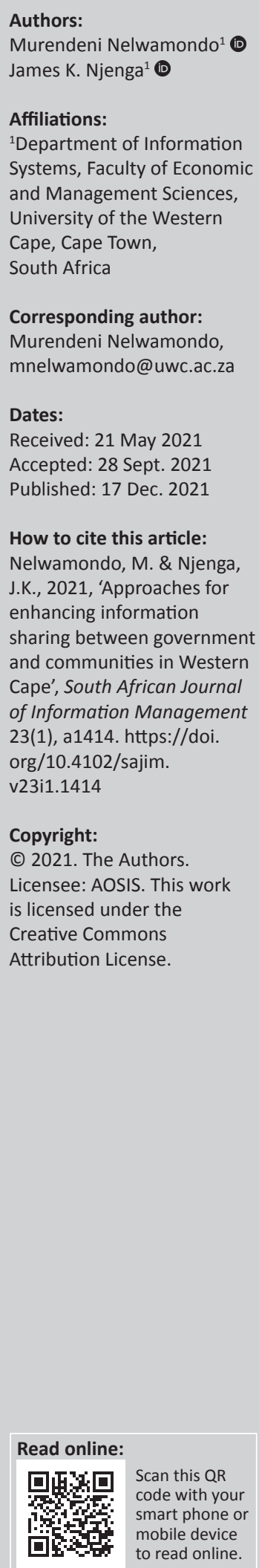

Background: The Western Cape Provincial Government uses digital intermediaries to facilitate information sharing between individuals, communities and the government. Digital intermediaries are shared facilities where communities can visit and have access to information and communication technology (ICT) and the internet. Communities benefit economically, socially and politically by using free access to ICT and the internet from intermediaries' facilities to share information with the government. There seem to be disparities between the roles of the different stakeholders in information sharing. These disparities often result in poor communication between the government and communities, and also poor government services delivery.

Objectives: This research investigated how intermediaries can enhance information sharing between government and communities in the Western Cape Province.

Method: This study adopted a qualitative research approach by using semi-structured interviews. Purposive sampling was used to collect qualitative data from 15 participants from different intermediaries' staff in the Western Cape Province. A narrative analysis approach was used to analyse the data.

Results: The study found that intermediaries intermediate between communities and the government by providing free access to ICTs, provide basic computer training and access to computing resources and serving as an information hub. The study also found that operating hours, lack of resources, skilled staff and communication challenges adversely affect information sharing.

Conclusion: This study recommended that intermediaries are supported to increase the number of resources and facilities and the number and levels of training in the province to cater for more communities. This study further recommended an increase on operational hours, and communication channels between the government and intermediaries.

Keywords: government; intermediary; information sharing; ICT; Western Cape; information; community library; e-centre.

\section{Introduction}

Using information and communication technology (ICT) to share information is rapidly increasing worldwide (Gil, Cortés-Cediel \& Cantador 2019; Hashmi, Dahar \& Sharif 2019; Nwanekezie, Choudrie \& Spencer 2016). Governments of many countries, including South Africa, use ICT to enhance information sharing with their citizens. The enhancement is crucial for the citizens' social, economic and political well-being (Furuholt \& Sæbø 2018; Hashmi et al. 2019; Nwanekezie et al. 2016).

Information sharing between communities and the government is essential in encouraging communities to participate in the political life and decisions made by the state (Falco, ZambranoVerratti \& Kleinhans 2019; Nwanekezie et al. 2016), and to address communities' issues such as health, safety and crime, and education (Van der Westhuizen \& Swart 2016). Worldwide, communities have actively participated in local issues and decision making within their communities, which increase the effectiveness of governance and efficiency in governments' delivery of services to the citizens (Falco \& Kleinhans 2018; Gil et al. 2019).

Even though the Western Cape Provincial Government (WCPG) has expanded its services and information online through ICT and enhanced public participation, there are still digitally divided communities. These communities do not have access to modern ICTs (Nwanekezie et al. 2016; Stoltenkamp, Kabaka \& Kies 2013), and they often cannot use ICT to share information with the 
government (Lediga \& Fombad 2018; Nwanekezie et al. 2016). These communities often lose out on opportunities to access timeous government information and miss out on the opportunity to participate in political life and decisions made by the government. The inability to share information also leads to the government not knowing issues, suggestions, and challenges faced by communities, thus resulting in inefficient government service delivery (Furuholt \& Sæbø 2018).

In response, both the South African national government and WCPG have established initiatives to resolve and reduce the digital divide challenge. This was achieved by building public libraries and E-centres with affordable ICT access for the communities (Kapondera \& Namusanya 2017; Watat \& Jonathan 2020), which act as intermediaries between the citizens and the government. These intermediaries serve as facilities where communities can visit, access government information and services, and have free or affordable access to ICT.

Despite the best efforts of the government and other stakeholders involved in the intermediaries, there seem to be disparities between the roles of the different stakeholders in information sharing (Chigona et al. 2010; Lwoga \& Chigona 2018). These disparities are caused by, amongst others, the intermediaries' low level of computer literacy, lack of understanding of how to adapt to using the new technology that might require more time than they could afford, inadequate infrastructure and a severe shortage of qualified staff (Lwoga \& Chigona 2020; Stoltenkamp et al. 2013). These disparities often result in poor communication between the intermediaries, government and communities, and poor government services delivery. The communities miss opportunities to access timeous and accurate information, and the government might not precisely know services desired by the communities which often results in poor service delivery.

\section{Objectives}

This research investigates how intermediaries can enhance information sharing between government and communities in some locations in the Western Cape Province. The following objectives guided the study:

- Assess the current state of information sharing between communities and government.

- Investigate the intermediate roles of intermediaries in enhancing information sharing between the government and communities.

- Explore challenges faced by intermediaries in enhancing information sharing between the government and communities.

- Suggest recommendations for enhancing information sharing between communities and the government.

\section{Literature review}

It is important to understand why and how communities use intermediaries` premises facilities to share information with the government. This section achieved this by discussing public participation in governance, the role of intermediaries in information sharing, and the challenges that intermediaries face that affect information sharing between communities and the government.

\section{Public participation in governance}

Information sharing between communities and the government is essential to encourage community participation in political life and decisions made by the state (Gil et al. 2019; Nwanekezie et al. 2016), and to address communities' issues and services such as health, safety and crime, and education (Lim et al. 2018; Van der Westhuizen \& Swart 2016). When communities participate in public matters and share information with the government, the government will become more aware about communities' issues, improving overall government service delivery (Gil et al. 2019; Lim et al. 2018). Therefore, public participation is an essential feature for democracy and, in most cases, an enabler for efficient service delivery by the government (Falco \& Kleinhans 2018; Gil et al. 2019).

\section{Current approaches for information sharing between communities and government}

Governments around the globe, including South Africa, are using ICT as a strategy to enhance information sharing with communities besides the traditional (face-to-face) approach (Aji, Tsuroyya \& Dewi 2018; Nwanekezie et al. 2016). This digital strategy includes enhancing information sharing and providing services using ICT, including electronic government (e-government) and mobile government (m-government) platforms. This strategy helps communities to have access to accurate and timeous information. Communities can use digital platforms such as forums on government websites, telephone, and electronic mail (email) to send suggestions, complaints, and comments to the government (Kanaan et al. 2019; Nwanekezie et al. 2016).

Despite the availability of the ICT approach for information sharing, some communities still prefer the traditional approach. However, the traditional approach is associated with challenges such as lack of timeous and accurate information, thus excluding their involvement in publicly participating in matters that affect them (Kanaan et al. 2019; Memarzadeh \& Jahany 2014; Sandoval-Almazan \& GilGarcia 2012). Some communities still do not have access or do not know how to use ICT to communicate with the government. The South African government established initiatives where communities can visit public spaces and use facilities to share information with the government. These establishments are referred to as intermediaries.

\section{Role of intermediaries in information sharing between communities and the government}

An intermediary denotes a middle party that serves as a bridge between two or more parties. A social and a digital intermediate serves a similar purpose: providing information and services to communities, and both terms can be used together as an intermediary. For this study, intermediaries are public community centres and libraries, including those who manage 
and work at those facilities. These are public facilities that communities can visit and use available ICTs and the internet to share information with the government (Kapondera \& Namusanya 2017). Digital intermediaries facilitate public participation and information sharing between the government and communities (Furuholt \& Sæbø 2018). Intermediaries provide free access to ICT, provide basic ICT training, and serve as an information hub (Chege, Kiplang'at \& Rotich 2019; Gil et al. 2019; Kapondera \& Namusanya 2017). The following section will discuss the roles played by intermediaries in assisting communities to share information with the government.

While intermediaries serve as places where communities can visit and access ICT, printing, basic computer training, and other ICT services (Kapondera \& Namusanya 2017; Stoltenkamp et al. 2013). Communities can have free access to ICT, especially those travelling long distances to access government offices' information and services (Kapondera \& Namusanya 2017; Lwoga \& Chigona 2020). Using the facilities found in the intermediaries can lower costs incurred whilst interacting with the government, especially where the government offices are far from the communities (Alenezi et al. 2017; Baeuo, Rahim \& Alaraibi 2016). Even though some communities might save travelling costs, some communities far from the intermediaries might still have to incur travelling costs to reach the nearest intermediary.

The digitally divided communities that, amongst others, lack basic ICT skills face challenges when using ICT to share information with the government (Lediga \& Fombad 2018; Nwanekezie et al. 2016). To address the lack of skills, intermediaries provide communities with free basic computer training to increase opportunities for marginalised communities and enhance public participation (Gcora et al. 2015; Kapondera \& Namusanya 2017; Lwoga \& Chigona 2018). The training allows communities to gain computer skills to access government information and resources and improve their lives by participating in government programmes (Kapondera \& Namusanya 2017; Lwoga \& Chigona 2018).

\section{Facilitation of information sharing between government and communities}

Digital intermediaries have ICTs within their premises. These technologies include telephones, computers connected to the internet and faxing machines they can use to facilitate information sharing between communities and the government (Furuholt \& Sæbø 2018; Lwoga \& Chigona 2018). Intermediaries assist communities by helping them create personal email accounts through which they can send and receive messages from the government (Nwanekezie et al. 2016). Sometimes, intermediaries may allow communities to use telephones in the premises to call government officials (Furuholt \& Sæbø 2018). Intermediaries also facilitate information sharing by assisting communities to access and navigate through government websites. Intermediaries train communities on how to use available ICTs so that they can use platforms such as email and the internet to share information with the government (Kapondera \& Namusanya
2017). Notably, this facilitation enhances information sharing between communities and the government.

\section{Intermediaries' challenges affecting information sharing}

Despite the government providing communities with various information and allowing communities to share information with the government, enhancing collaboration in public policy formulation, some communities still lack sufficient financial resources and means to physically visit government's offices (Gil et al. 2019). Communities are provided with digital platforms to access ICTs facilities available at the intermediaries to share online distributed government information (Gil et al. 2019). However, many challenges are hindering the enhancement of information sharing between communities and the government. These challenges include: shortage of skilled labour, lack of adequate resources, and operating hours of the intermediaries (Kapondera \& Hart 2016; Kapondera \& Namusanya 2017; Lwoga \& Chigona 2018; Uys \& Pather 2017).

Shortage of skilled staff affects intermediaries' ability to support and manage the facilities (Kapondera \& Hart 2016; Kapondera \& Namusanya 2017). The lack of ICT skills of the intermediaries' staff may affect them in assisting communities to share information with the government, since they may not be able to assist those communities which are lacking or are without ICT skills. As communities are expected to learn ICT skills such as basic computer literacy (Furuholt \& Sæbø 2018), the intermediaries' employees need to possess such skills to assist them. Intermediaries' managers and staff receive basic ICT training that aims to provide them with ICT skills that they can use to assist communities in sharing information with the government. However, the literature highlights that the intermediaries' staff should acquire more than just basic ICT skills for them to assist and train communities. Furthermore, intermediaries operate with insufficient resources, including financial, human, facilities and infrastructure found within their premises (Kapondera \& Namusanya 2017; Lwoga \& Chigona 2018; Uys \& Pather 2017). The local and provincial government provides the intermediaries' infrastructure and facilities, but the funding provided to maintain and service the facilities is insufficient (Gcora et al. 2015; Kapondera \& Hart 2016; Lwoga \& Chigona 2018).

Intermediaries also have to contend with poor infrastructure and shortage of resources such as technologies (Breitenbach 2013; Hassan et al. 2010; Kapondera \& Namusanya 2017). At some intermediaries, technologies are outdated or nonfunctional. Breitenbach (2013) and Gcora et al. (2015) stated that non-functional technologies can affect the way intermediaries provide their services and how communities use these facilities. Mbatha (2016) added that outdated technologies and software can affect how communities use the intermediaries' premises and facilities. Obsolete technologies can negatively affect the way an intermediary renders the service. It takes a long time to fix, update, and maintain the broken and outdated technologies in some cases (Mbatha 2016), which negatively affects services offered to communities. 
Shortage of facilities such as ICT is a common problem that intermediaries and communities face. Some intermediaries do not have enough computers, and their internet connections are inadequate and slow (Gcora et al. 2015; Kapondera \& Namusanya 2017; Nkosi \& Mekuria 2010). Mbatha (2016) additionally noted that the computers are usually not working in most intermediaries, and sometimes the internet is offline. Operating hours of intermediaries is also a challenge that some communities face. In some cases, intermediaries operate from Monday to Saturday during government-set working hours (Kapondera \& Namusanya 2017). As a result of the operating hours and the number of communities each intermediary serves, each community member is allocated only $45 \mathrm{~min}$ daily to use computers and the internet (Stoltenkamp et al. 2013). While more intermediaries are being built to provide information and services to underserved communities, communities are faced with varying intermediaries operations (Uys \& Pather 2017). The operating hours of intermediaries affect the accessibility and the use of facilities in the intermediaries (Gcora et al. 2015). The operating hours' challenge might mean that the staff might not assist all communities seeking assistance simultaneously and within the allocated time to use computers in a day. Furthermore, communities that are busy or working during the formal government working hours find it challenging to use intermediaries' facilities because of the operating hours.

\section{Methodology}

This study used a qualitative approach to understand how intermediaries can enhance information sharing between the government and communities in the Western Cape Province. This research required in-depth engagement with the intermediaries to get a comprehensive insight into the problem being addressed. Data were collected from 15 participants from different intermediaries in the Western Cape Province. All intermediaries were part of the government initiative 'Smart Cape'. Data were collected through semi-structured interviews with the participants. Eleven participants are intermediaries' managers, and the remaining participants are general staff who serve roles such as those of a manager and assistant to the managers. Purposive sampling was a suitable way to choose the sample. In this study, the interpretive paradigm was more pertinent to explore meanings and knowledge about the intermediation role in information sharing between communities and the government. While people interpret reality differently, an interpretive approach resulted in an understanding of the phenomena which was being investigated from different participants in this study.

Purposive sampling was chosen to sample staff in the e-centres or community library. A sample was drawn from a pool of intermediaries that the government established. Two intermediaries were from Thusong centres, while the remaining were from Smart Cape Access centres. Both types of centres serve different communities within the Western Cape by offering them free access to ICTs, basic computer training, and access to government information and services.
This study collected qualitative data through semi-structured interviews from 15 participants that took place at the comfortability of the intermediaries' geographical locations. Interviews were used to gain an in-depth understanding of the research problem being investigated. As far as the study collected qualitative data and data analysis were concerned, a narrative analysis with the adoption of Atlas.ti, a qualitative data analysis tool, was used to support the analysis and coding of the data. The study followed a four-stage methodology to analyse the data. The first stage after collecting data was transcribing and translating data to English for some cases where participants responded in Afrikaans or isiXhosa. The data was captured on Microsoft Excel, and related data were grouped to identify themes. The next stage was to edit Atlas.ti's headers to match with the headings saved on the Microsoft Excel spreadsheet and import the spreadsheet to Atlas.ti. All responses from participants were saved in an individual document. The next stage was to query the data by finding answers, grouping all related responses, and grouping them as themes. The last stage was to link the identified themes with the research objectives, and finally, the last stage involved carefully describing the results. These stages were transcribing interviews, grouping related data, linking data to the conceptual framework, and analysing and describing results (Scott 2009).

\section{Results}

The findings are based on the perceptions of the participants from intermediaries within the Western Cape Province. Two core themes emerged from the data: the role of intermediaries in enhancing information between the government and communities and challenges faced by intermediaries affecting information sharing.

\section{Role of intermediaries in enhancing information sharing between communities and the government}

Intermediaries play an intermediation role in enhancing information sharing between communities and the government. The study found that the intermediate role is achieved by providing communities with free access to ICTs and basic computer training and intermediaries serving as an information hub.

\section{Providing free access to information and communication technology}

The study found that amongst other available ICTs, each intermediary is equipped with computers connected to the internet. Some intermediaries have a Wireless Fidelity (Wi-Fi) connectivity, whereby communities can connect their mobile devices to the internet and access government information:

'We have the WiFi, we got a free Wi-Fi, it is for everyone; you just need to have a library card first and then a good thing about it is that you get $500 \mathrm{MB}$ every month for free.' (Participant 6, female, E-Centre manager, 34 years)

'We've got 15 computers upstairs that are for free, you just need to have a library card to use them and, we got 5 computers here, but these ones are only for e-resources.' (Participant 3, female, E-Centre manager, 49 years) 
'In this centre we have computers, free $\mathrm{Wi}-\mathrm{Fi}$, telephone, smart phones, library management software, office operations software, Smart Cape, social media networks, email, intranet, etc.' (Participant 11, male, E-Centre manager, 35 years)

'We have 5 computers connected to the internet, keyboards, mouse; we also have one printer, therefore the centre manager and the developing manager is in charge of this printer.' (Participant 1, female, E-Centre manager, 28 years)

The findings from the study show that intermediaries do not have the same number of computers on the premises. One reason is the number of communities being served within a specific area. However, communities can make use of the available facilities to communicate with the government.

\section{Providing basic computer training}

The study found that six intermediaries offer basic computer training to the communities. The basic computer training aims to equip communities with skills to use a computer and the internet. The skills acquired from the computer training also assist communities to share information with the government:

'[... B] ]asic things like how to start a computer, how to register yourself, how to log into emails, and how to do a word document, excel, etc.' (Participant 9, female, E-Centre staff member, 30 years)

'We also have a computer literacy that we give free of charge to the public, those who don't know how to use a computer we do teach them how to.' (Participant 2, female, E-Centre manager, 41 years)

In one intermediary who does not offer computer training, they assist the communities in need:

'We don't really have a person who trains, who is more advanced or who understands computers better.' (Participant 4, female, E-Centre manager, 37 years)

\section{Intermediaries serving as an information hub}

The intermediaries provide information to communities. This information is business information, government information, information about intermediaries and their services, jobs, and research information. When communities visit the intermediaries, they may use ICT to access any information provided should they wish to do so. Information is also provided to communities through pamphlets, posters, word of mouth, newspapers provided by the government or printed by the intermediaries. Communities seeking such information can find such information when they visit the intermediaries, and communities can benefit from receiving the information they are seeking:

'[W]e are also involved in small businesses, people who are maybe looking for [on] information on how to start a business and so on we have a section for that, so we have to make sure that section is up to date.' (Participant 2, female, E-Centre manager, 41 years)

'We have a section for jobs, where people come and they ask for information about jobs vacancies, we have newspapers that we keep aside then people can come and have a look and make copies if they want.' (Participant 7, male, E-Centre staff member, 30 years)

'We have print-outs of all the careers that the City of Cape Town is offering. We update it on a daily basis if there is something new.' (Participant 11, male, E-Centre manager, 35 years)
'Our role is to help people get the information they need at the library, for example, information relating to employment opportunities.' (Participant 8, female, E-Centre manager, 44 years)

Even though most of the information searched and required by communities is electronically accessible through ICT, intermediaries must also ensure that information supplied to them by the government and other non-governmental organisations that they print for communities is timeous. This is done to ensure that the communities have access to timeous and accurate information, as also the latest editions of books:

'[W]e are also involved in small businesses, people who are maybe looking for information on how to start a business and so on we have a section for that, we have to make sure that that section is up to date.' (Participant 5, male, E-Centre manager, 51 years)

'We must empty the returned books shelf every morning because if we don't do our shelving and patron phones and they need a book then we won't find it in the shelf.' (Participant 3, female, E-Centre manager, 49 years)

Therefore, intermediaries ensure that the information they provide to communities is timeous and accurate. Even though the information is provided through the internet, and intermediaries do not control it, however, they can ensure that they assist communities in accessing recent and updated content on the internet. Having access to timeous and accurate information assists communities to be up to date with the information from the government, which will help them make informed decisions regarding public matters that affect them. Only when communities share information with the government, the government receives such information and is aware of communities' needs, enhancing the government's information and service delivery.

\section{Facilitation of information sharing between communities and the government}

The study found that intermediaries currently facilitate information sharing between the government and communities. All participants, except one, stated that they play a role in assisting communities with sharing information with their government. The study found that there is a need for communities to communicate with the government. It was found that some communities communicate with the government to have access to government information. This information includes, amongst other, information regarding social grants applications, information about the South African Revenue Services (SARS), and information about vacant government jobs. Responses from participants endorse this:

'Basically the need for them to communicate with the government is that they can know about the job vacancies which are available on the government website.' (Participant 6, female, E-Centre manager, 34 years)

'[...T] he main thing is that they are just looking for information.' (Participant 10, male, E-Centre manager, 34 years)

Participants also justified why communities should make use of intermediaries to share information with the government. The reason amongst others is the cost and time to visit the government offices: 
'You have to go through different modes of transport to visit the government offices/departments and that is very costly.' (Participant 1, female, E-Centre manager, 28 years)

'The best way for them to communicate with the government is if they come and visit our centre and go online because they won't be able to physically go to the offices or department.' (Participant 8, female, E-Centre manager, 44 years)

'It's because most of the government is not with the people. So [the] internet is the one that makes things to be much easier, faster and that is the only connection we use.' (Participant 10, male, E-Centre manager, 34 years)

The study also found that some communities that stay close to government offices are not affected by transport costs to go to government offices physically. However, sometimes, they may choose to visit the intermediary to avoid the long waiting period at the government offices, or an appointment they need to make to see a certain person:

'[...B] ecause you have to make an appointment in order to see a very certain person who works with certain departments.' (Participant 3, female, E-Centre manager, 49 years)

The study also found that some intermediaries help facilitate information sharing between the government and communities. The first thing that was noted from the responses was that most of the communities that visit the intermediaries are not computer literate, and the intermediaries will then train them on how to use the computer and the internet for them to communicate with the government on their own:

'You will find that most of the people that need these services are not computer literate. ... So that is our job that when they come, we facilitate the process, we help them step by step on how to do it.' (Participant 5, male, E-Centre manager, 51 years)

' $[\ldots W]$ e will assist them doing that so that they can know how to do it themselves in the future.' (Participant 1, female, E-Centre manager, 28 years)

It was found from the study that some intermediaries facilitate information sharing between communities and the government by creating free email accounts for the communities and help them use those email accounts to communicate with the government:

'We assist them to create an email account.' (Participant 8, female, E-Centre manager, 44 years)

Another participant stated that they facilitate information sharing between communities and the government by putting posters from the government on the noticeboards for communities to read.

In some cases, intermediaries monitor what the communities send to the government when they assist them by ensuring that if the communities are sending messages to the government, it should be about matters about the community or community concerns:

'Any form of communication that one passes or when one communicates to the government should be of community concern not politically concerned.' (Participant 8, female, E-Centre manager, 44 years)

Another intermediary stated that they do not monitor or intervene with communities when using the internet or sending out emails to the government. The intermediaries will facilitate the communication process by helping the communities to send the emails regardless of the recipient:

'[...I]f the people want answers or they want a website where they can complain; the only thing that we do is that we just guide them to that website and then they go to there and we can't intervene.' (Participant 5, male, E-Centre manager, 51 years)

'They just write whatever and then they just send to whoever; that's how they communicate.' (Participant 10, male, E-Centre manager, 34 years)

\section{Challenges faced by intermediaries affecting information sharing}

The study found that a lack of effective communication between intermediaries and the government is a challenge faced by some intermediaries that would choose to communicate with the government. One respondent stated that sometimes they do not get answers from the government, and even if they receive responses, it is usually unexpected:

'I'd say the challenges would be when you don't get the answer that you were wishing for, or sometimes people will interpret the response in their wrong perspective.' (Participant 6, female, E-Centre manager, 34 years)

'Of course, the government has all these challenges because you made [an] application and you don't get a response and then you must resort to some other ways of getting the information like you have to contact someone there and make inquiries.' (Participant 6, female, E-Centre manager, 34 years)

Another participant showed they do not communicate directly with the government, and they have to communicate to the government through their managers:

'I can't answer that one because we only communicate with our seniors, and then they're the ones who are communicating with the government.' (Participant 4, female, E-Centre manager, 37 years)

The ineffective communication brings a misunderstanding between the government officials and the intermediaries, affecting how they render their services. The challenge of the reporting channel where they must communicate with their seniors, who will then communicate with the government, takes time, resulting in delayed responses from the government.

The study found that sometimes intermediaries will call for community meetings to address some of the government services offered by intermediaries, but some communities do not attend those meetings. These meetings are often announced verbally as some communities do not have computer skills, and calling the meetings through the email platform would not be efficient:

'It's very clear you can organise a meeting then you find that it's only the regular people that come to attend those meetings, and this is challenging.' (Participant 10, male, E-Centre manager, 34 years) 
Another participant added that the communities' lack of computer skills becomes a serious problem because calling for a meeting through word of mouth takes time, and some communities do not even receive the message. They could use other means such as email services, but some communities lack computer skills:

'Communities do not have computer skills.' (Participant 15, male, E-Centre manager, 41 years)

The study also found that some communities are very impatient when intermediaries train them to use computers, the internet and email services. This becomes a challenge because some communities cannot read and respond even if intermediaries send out emails:

'Sometimes when you are teaching a person, they are not patient. They would want to go and the time you dedicated to help them to gain skills is wasted.' (Participant 2, female, E-Centre manager, 41 years)

'Most of the time I don't know why when you give them a computer, they are always afraid of a computer.' (Participant 9, female, E-Centre staff member, 30 years)

\section{Discussions}

The study found that intermediaries serve as an information hub. This information ranges from business information, career information, and information about the communities, to government information. Communities visit intermediaries and make use of the internet and email to communicate with the government. The findings from the study echo the literature that state that some communities might have minimal knowledge and ability to make use of the internet and email. Intermediaries must possess ICT skills to assist communities unable to use ICT to communicate with the government. The study found that participants have ICT skills that they use to assist communities in communicating with the government. Communities can save on travelling costs to visit government offices (Kapondera \& Namusanya 2017; Stoltenkamp et al. 2013).

The study also found that there are different technologies available to intermediaries and for the communities to use. All intermediaries are equipped with technologies such as computers that are connected to the internet. These computers assist communities to share information with the government. However, the study found that not all intermediaries have the same technologies in their respective premises. The technologies found at all the intermediaries' premises were: computers, printers, copy machines, and telephones. Intermediaries serve as a place where communities can visit and access ICT, printing, basic computer training, and other ICT services (Kapondera \& Namusanya 2017; Stoltenkamp et al. 2013). The study found that available ICTs assist communities to communicate with the government. Therefore, it is crucial to ensure that all technologies work and serve their purposes to enhance information sharing between communities and the government.

Intermediaries also enhance information sharing between the government and communities by providing basic computer training that assists communities in using ICT and the internet. The finding supports the literature stating that intermediaries provide basic computer literacy lessons (Kapondera \& Namusanya 2017; Lwoga \& Chigona 2018; Stoltenkamp et al. 2013). After communities receive the training, they might use ICTs available to communicate with the government and access online government information and services. However, the literature does not show or prove if that is met.

The shortage of skilled intermediaries' staff is one challenge that impacts how communities use technologies to share information with the government. In terms of shortage of skilled staff, intermediaries' managers and staff should receive training that could help them acquire skills to assist communities in using technologies (Kapondera \& Namusanya 2017; Stoltenkamp et al. 2013). In addition, some intermediaries face challenges of lack of adequate resources and operating hours. Operating hours is the limited time during which intermediaries are open to serve communities. The study found that not all intermediaries have a similar type, quality and same number of ICTs. It can take up to 6 months for some intermediaries to repair a broken technology such as a computer. Each community member is allocated 45 min daily to use the available computer and the internet, which is barely enough for most members (Kapondera \& Hart 2016; Stoltenkamp et al. 2013; Uys \& Pather 2017). The study also found that some intermediaries operate from Monday to Friday. This might impact communities that can not use intermediaries during the week and are only available during the weekend when intermediaries are not operational, thus affecting the use of ICTs to communicate with the government. The published literature does not show how the shortage of skilled intermediaries affects how communities share information with the government.

Intermediaries face challenges when communicating with the government and with communities. The major challenge is ineffective communication faced by intermediaries, which is slow responses and ineffective communication. This supports the literature findings that state that the South African government undoubtedly faces challenges such as slow response rates to communities' requests, inconvenient hours offered by the government institutions, and long distances to reach government offices (Mawela, Ochara \& Twinomurinzi 2017):

'I think our biggest challenge is the marketing, to market the E-centre in the community.' (Participant 13, female, E-Centre staff member, 39 years )

This challenge may affect how communities communicate with the government through intermediaries, because if they do not know the services offered, they may not visit intermediaries.

\section{Conclusion}

This study explored the intermediation role in information sharing between the government and communities in Western Cape, where intermediaries provide information to 
communities and serve as an intermediate between communities and the government.

Communities can realise many economic, social and communication benefits from using intermediaries (Kapondera \& Namusanya 2017; Lwoga \& Chigona 2018). Communities benefit economically and socially when they use these intermediaries and their services, including free basic computer training, saving travelling costs to visit government offices, and having free access to ICTs, government information, and services. The findings from the study echo the findings from the literature that state communities benefit from free services and cost-saving (Lwoga \& Chigona 2016; Stoltenkamp et al. 2013). Some community members can save transport fares by visiting intermediaries (Kapondera \& Namusanya 2017; Stoltenkamp et al. 2013). Using the facilities found in the intermediaries can lower costs incurred to interact with the government, especially when the government offices are far from the communities (Alenezi et al. 2017; Baeuo et al. 2016; Sarrayrih \& Sriram 2015). Communities in the Western Cape Province could benefit from using intermediaries to share information to save transport fares and all costs associated with communicating with the government if they were using their technologies. Therefore, communities that reside close to intermediaries can use available technologies by the intermediaries to enhance information sharing.

In offering these services, intermediaries face challenges of limited operational hours that affect the time allocated to each community member to use the services, lack of skilled staff and lack of adequate resources. The study also found that a common challenge is perceived ineffective communication between intermediaries, government, and communities.

\section{A participant stated that:}

'I'd say the challenges would be when you don't get the answer that you were wishing for or sometimes people will interpret the response in their wrong perspective.' (Participant 6, female, E-Centre manager, 34 years)

Another participant added:
'most of the time I don't know why when you give them a computer they are always afraid of a computer.' (Participant 9, female, E-Centre staff member, 30 years)

The Western Cape Government communities are affected by challenges intermediaries face, including limited operating hours, lack of skilled staff, and lack of adequate resources. These challenges affect the way intermediaries' facilities communicate with the government, thus slowing down communication between communities and the government.

Several measures are recommended to enhance information sharing between communities and the government by using the intermediaries: increase resources, increase operational hours, improve internet speed, increase communication channels between the government and intermediaries, increase number and levels of training, and provide more intermediaries. Increasing the number of resources was the first suggestion.
This includes the number of computers provided in every intermediary's premises. Furthermore, the number of staff could be increased and the number of technicians to assist with repairing and maintaining non-functional ICTs. Besides, the number of training should also be increased to provide intermediaries staff with adequate skills to assist with information sharing between communities and the government. There is a need for further research to determine if the training received assist intermediaries to share information with the government. It will be interesting to explore the aspects covered in that training to determine if those training can assist intermediaries in enhancing information sharing and determining if there should be room for improvement.

Intermediaries, where possible, could extend operational hours and operate every day. Moreover, after increasing the number of resources, intermediaries should also extend the time allocated to each community to use the computer every day to an accepted time frame by communities. Therefore, it proves that if the government and intermediaries address the challenges intermediaries face, that will enhance information sharing between the government and communities in the Western Cape.

This study focused on the intermediaries in the Western Cape Province and, hence, is not a representative of intermediaries in other provinces in South Africa. Therefore, it is recommended that future research is expanded to other provinces. The focus on communities and intermediaries also means that government representatives were not participants in the research. Therefore, it is also recommended that future research participants should also include government officials. This will help explore views from communities, intermediaries and the government to develop a conceptual framework that can enhance information sharing between communities and the government in Western Cape, and the rest of the country.

\section{Acknowledgements}

The authors would like to thank all the participants who participated in this study.

\section{Competing interests}

The authors have declared that no competing interest exists.

\section{Author's contributions}

Both the authors contributed to the design and implementation of the research, to the analysis of the results and to the writing of the article.

\section{Ethical considerations}

This article followed all ethical standards for a research without direct contact with human or animal subjects.

\section{Funding information}

This research did not receive any specific grant from any agency in the public, commercial or not-for-profit sectors. 


\section{Data availability}

The data that support the findings of this study are available on request from the corresponding author, M.N. The data are not publicly available because of protection of participants' information.

\section{Disclaimer}

The views and opinions expressed in this article are those of the authors and do not necessarily reflect the official policy or position of any affiliated agency of the authors.

\section{References}

Aji, G.G., Tsuroyya \& Dewi, P.A.R., 2018, 'Bridging communication between public and government: A case study on kim surabaya', Journal of Physics: Conference Series 953(1), 012194. https://doi.org/10.1088/1742-6596/953/1/012194

Alenezi, H., Tarhini, A., Masa, E., Alalwan, A. \& Al-Qirim, N., 2017, 'Factors affecting the adoption of e-government in Kuwait: A qualitative study', The Electronic Journal of e-Government 15(2), 84-102. viewed 13 March 2021, from https:// academic-publishing.org/index.php/ejeg/article/view/642.

Baeuo, M.O., Rahim, N.Z.B. \& Alaraibi, A.A.M., 2016, 'Technology aspects of e-government readiness in developing countries: A review of the literature', Computer and Information Science 9(4), 1-12. https://doi.org/10.5539/cis.v9n4p1

Breitenbach, M.C., 2013, 'Telecentres for sustainable rural development: Review and case study of a South African rural telecentre', Development Southern Africa 30(2), 262-278. https://doi.org/10.1080/0376835X.2013.797229

Chege, C.W., Kiplang'at, J. \& Rotich, D.C., 2019, 'Information services provided by Maarifa telecentres to rural communities in ASALs in Kenya', Inkanyiso: Journal of Humanities and Social Sciences 11(1),50-68, viewed 28 November 2020, from https://www.researchgate.net/publication/339457314_Information_services https://www.researchgate.net/publication/339457314_Information_services

Chigona, W., Roode, D., Nazeer, N. \& Pinnock, B., 2010, 'Investigating the impact of stakeholder management on the implemention of a public access project : Case of
Smart Cape', South African Journal of Business Management 4(2), 1-16. https:// Smart Cape', South African Journal
doi.org/10.4102/sajbm.v41i2.517

Falco, E. \& Kleinhans, R., 2018, 'Beyond information-sharing: A typology of government challenges and requirements for two-way social media communication with challenges and requirements for two-way social media communication with citizens', Electronic Journal of e-Government 16(1), 18-31, viewed 17 March 2021 from https://www.researchgate.net/publication/325285742_Beyond_InformationSharing_A_Typology_Of_Government_Challenges_And_Requirements_For_TwoWay_Social_Media_Communication_With_Citizens.

Falco, E., Zambrano-Verratti, J. \& Kleinhans, R., 2019, 'Web-based participatory mapping in informal settlements: The slums of Caracas, Venezuela', Habitat International 94(3), 1-20, viewed 17 March 2021, from https://doi.org/10.1016/j. International 94(3), 1-20,
habitatint.2019.102038

Furuholt, B. \& Sæb $\varnothing, \varnothing$., 2018, 'The role telecentres play in providing e-government services in rural areas: A longitudinal study of Internet access and e-government services in Tanzania', Electronic Journal of Information Systems in Developing Countries 84(1), 1-14. https://doi.org/10.1002/isd2.12006

Gcora, N., Gopeni, A., Tuswa, M., Lwoga, T. \& Chigona, W., 2015, 'The challenges rura women face in using Telecentres: The case of the Eastern Cape province', in 2015 proceedings of the 9th IDIA conference, IDIA2015, Nungwi, Zanzibar, pp. 84-95, viewed 30 March 2021, from https://www.researchgate.net/publication/286454596_The challenges rural women face in using_Telecentres The case_of the Eastern Cape_Province.

Gil, O., Cortés-Cediel, M.E. \& Cantador, I., 2019, 'Citizen participation and the rise of digital media platforms in smart governance and smart cities', International Journa of E-Planning Research 8(1), 19-34. https://doi.org/10.4018/IJEPR.2019010102

Hashmi, Z., Dahar, M. \& Sharif, A., 2019, 'Role of information and communication technology in motivating, university undergraduate students towards a learning task in public sector universities of Rawalpindi City', Sociology and Criminology Open Access 7(1), 1-7. https://doi.org/10.35248/2375-4435.19.7.196

Hassan, S., Yusof, Y., Amir, M., Seman, A. \& Sheik, W.R., 2010, Impact analysis on utilisation of telecenter: The case of telecentre in Baling, pp. 14-19, viewed 27 December 2020, from https://www.semanticscholar.org/paper/Impact-analysison-utilization-of-telecenter\%3A-The-Hassan-Yusof/07ac241d46b9aa766b5a2080 c83dc16b3df2a70a.
Kanaan, R.K., Abumatar, G., Al-Lozi, P.D.M. \& Abu Hussein, A.M., 2019, 'Implementation of M-government: Leveraging mobile technology to streamline the e-governance framework', Journal of Social Sciences (COES\&RJ-JSS) 8(3), 495-508. https://doi. org/10.25255/jss.2019.8.3.495.508

Kapondera, S.K. \& Hart, G., 2016, 'The use of multipurpose community telecentres and their services in Malawi: The case of Lupaso community telecentre', South African Journal of Libraries and Information Science 82(1), 13-25. https://doi. African Journal of Libra
org/10.7553/82-1-1589

Kapondera, S.K. \& Namusanya, D.M., 2017, 'Uses, benefits and challenges of using rural community telecentres as tools for development: The case of Vikwa community telecentre in Kasungu, Malawi', Journal of Development and Communication Studies 5(1), 1-21. https://doi.org/10.4314/jdcs.v5i1.1

Lediga, M.M. \& Fombad, M.C., 2018, 'The use of information and communication technologies in public libraries in South Africa as tools for bridging the digital divide: The case of the Kempton Park public library', Public Library Quarterly 37(3), 296-305. https://doi.org/10.1080/01616846.2018.1471964

Lim, S., Abdul Malek, J., Hussain, M.Y. \& Tahir, Z., 2018, 'Citizen participation in building citizen-centric smart cities', Malaysian Journal of Society and Space 14(4), 42-53. https://doi.org/10.17576/geo-2018-1404-04

Lwoga, E.T. \& Chigona, W., 2016, 'Characteristics and factors that differentiate Internet users and non-users as information seekers: The case of rural women in Tanzania', Information Development 33, 1-16. https://doi.org/10.1177/ 0266666916669557

Lwoga, E.T. \& Chigona, W., 2018, 'Perception, usage and barriers towards the utilisation of the telecentre among rural women in Tanzania', Journal of Information, Communication and Ethics in Society 17(1), 2-16. https://doi. org/10.1108/JICES-01-2018-0004

Lwoga, E.T. \& Chigona, W., 2020, 'Telecenters and the expansion of human capabilities among rural women', Global Knowledge, Memory and Communication 69(7) 501-520. https://doi.org/10.1108/GKMC-11-2019-0136

Mawela, T., Ochara, N.M. \& Twinomurinzi, H., 2017, 'E-government implementation A reflection on South African municipalities', South African Computer Journal 29(1), 147-171. https://doi.org/10.18489/sacj.v29i1.444

Mbatha, B., 2016, 'Pushing the agenda of the information society: ICT diffusion in selected multipurpose community telecentres in South Africa', Information Development 32(4), 937-952. https://doi.org/10.1177/0266666915575544

Memarzadeh, G.R. \& Jahany, A.R., 2014, 'The presenting a model for municipalities e-readiness assessment', International Journal of Management and Business Research 4(2), 107-123.

Nkosi, M. \& Mekuria, F., 2010, 'Mobile government for improved public service provision in South Africa', in 2010 IST-Africa, pp 1-8, Durban, viewed 14 November 2020, from https://www.researchgate.net/publication/224230761 Mobile_government_for_improved_public_service_provision_in_South_Africa.

Nwanekezie, U., Choudrie, J. \& Spencer, N., 2016, 'Public sector online communication channel adoption and usage amongst older adults: A UK local government perspective', in 24th European conference on information systems, ECIS 2016, viewed 16 January 2021, from https://aisel.aisnet.org/ecis2016_rip/8/.

Sandoval-Almazan, R. \& Gil-Garcia, J.R., 2012, 'Are government internet portals evolving towards more interaction, participation, and collaboration? Revisiting the rhetoric of e-government among municipalities' Government Information Quarterly 29, 72-81. https://doi.org/10.1016/j.giq.2011.09.004

Sarrayrih, M.A. \& Sriram, B., 2015, 'Major challenges in developing a successful e-government: A review on the Sultanate of Oman', Journal of King Saud University - Computer and Information Sciences 27(2), 230-235. https://doi. org/10.1016/j.jksuci.2014.04.004

Scott, H., 2009, What is grounded theory?, Grounded Theory Institute, viewed 03 July 2018, from http://www.groundedtheoryonline.com/what-is-grounded-theory.

Stoltenkamp, J., Kabaka, M. \& Kies, C., 2013, 'Digital inclusion: Fundamentals of e-Centre management training programme (2012) a written analysis on community needs and experiences of ecentre managers (Western Cape)', in Edulearn13: 5th International conference on education and new learning technologies, Barcelona, Spain, pp. 3484-3493, viewed 19 December 2020, from technologies, Barcelona, Spain, pp. 3484-3493, viewed
https://library.iated.org/view/STOLTENKAMP2013DIG.

Uys, C. \& Pather, S., 2017, 'Government public access centres (PACs): A beacon of hope for marginalised communities', The Journal of Community Informatics 12 , 21-52. https://doi.org/10.15353/joci.v12i1.3237

Watat, J.K. \& Jonathan, M.G., 2020, 'Breaking the digital divide in Rural Africa', in AMCIS 2020 proceedings, pp. 1-10, viewed 13 March 2021, from https://aisel. aisnet.org/amcis2020/global_dev/global_dev/2.

Van der Westhuizen, M. \& Swart, I., 2016, 'The struggle against poverty, unemployment and social injustice in present-day South Africa: Exploring the involvement of the Dutch Reformed Church at congregational level', STJ / Stellenbosch Theological Journal 1(2), 731-760. https://doi.org/10.17570/stj.2015.v1n2.a35 